\title{
Innovating Neonatal Resuscitation Bags for Ease of Use in Diverse Locations
}

The Chinese emperor Huang-Ti (2698-2599 BCE) noted that newborn death from ventilatory failure was common in premature infants. ${ }^{1}$ Galen (129-199 CE) inflated the lungs of deceased animals with a bellows and concluded that the air movement causes the chest to rise. ${ }^{1,2}$ Between 1850 and 1950 , many techniques were used to resuscitate newborns, including swinging the infant upside down, ${ }^{1-3}$ rhythmic traction of the tongue, tickling, shaking, and yelling, ${ }^{2}$ and various other methods. In 1950, the first positivepressure device was created to inflate infant lungs. ${ }^{4}$ Since that time, flow- and self-inflating manual resuscitation bagvalve devices have been developed to manually support infants requiring ventilation. In more recent years, flowcontrolled pressure-limited T-piece devices, such as the Neopuff resuscitator (Fisher \& Paykel Healthcare, Auckland New Zealand), have also been designed for manual ventilation of infants. Current neonatal resuscitation guidelines specify that ventilation can be achieved with a flowinflating bag, ${ }^{5}$ self-inflating bag, $, 5,6$ or T-piece device. ${ }^{5}$

Statistics in 2010 on global child mortality show that over 700,000 neonates die annually from birth asphyxia, and this is the second largest cause of neonatal death in Africa, the Eastern Mediterranean, Western Pacific, and Southeast Asia. ${ }^{7}$ There may be an opportunity in this population to reduce mortalities especially in low-resource settings with an affordable and easy-to-use manual neonatal resuscitation bag. There are limited data comparing neonatal resuscitation equipment. Several studies have compared self-inflating neonatal resuscitation bags $^{8,9}$ and flow-inflating neonatal resuscitation bags and T-piece devices. $^{8-10}$ These studies have generally examined the effectiveness of maintaining a desired peak inspiratory pressure, breathing frequency, and PEEP and have found no significant differences between devices. There is a dearth of evidence examining resuscitation equipment that may be well suited for under-resourced locations or places where training may not be optimal.

\footnotetext{
Mr Emberger has disclosed no conflicts of interest.
}

Correspondence: John S Emberger Jr RRT-ACCS FAARC, Department of Respiratory Care, Christiana Care Health System, 4755 OgletownStanton Road, Newark, DE 19718. E-mail: jemberger@ christianacare.org.

DOI: $10.4187 /$ respcare. 04327
In this issue of Respiratory Care, Coffey et a ${ }^{11}$ examine the performance and acceptability of two self-inflating resuscitation bags for neonates. One of the bags is a commonly used device, and the other is a new design intended to be less expensive and easier to both use and clean, with

See the Original Study on Page 1227

a new mask to provide a better seal. The authors found a significant reduction in the percentage of breaths that delivered inadequate tidal volumes with the newer device. They also found a significant difference in ability to disassemble and reassemble the devices, favoring the newer device, which has fewer parts. The authors conclude that this new device may be suitable for both infrequent users and users in low-resource settings.

There are some important limitations of this study in understanding the context and applicability of the results. This is an in vitro bench study and, as such, may not translate directly to an actual clinical setting. The authors used only a single-lung model configuration and did not test a range of settings to be used. The study involved a small interdisciplinary group of caregivers from one location; a different set of caregivers from a different location may perform with different results. There are many different flow- and self-inflating devices available for neonatal resuscitation, and this study used only one comparison device. One must keep these limitations in mind. Despite these limitations, this is an important paper because innovative, lowcost, easy-to-use devices may be key in treating neonates who would otherwise become a mortality statistic with birth asphyxia in locations that may not have enough training or resources to handle neonatal resuscitation.

John S Emberger Jr RRT-ACCS FAARC Department of Respiratory Care Christiana Care Health System Newark, Delaware

\section{REFERENCES}

1. Wiswell TE, Gibson AT. Historical evolution of neonatal resuscitation. Elk Grove Village, IL: American Academy of Pediatrics Neonatal Resuscitation Program, Instructor Resources; 2005. 


\section{Neonatal Resuscitation Bags}

2. Raju T. History of neonatal resuscitation: tales of heroism and desperation. Clin Perinatol 1999;26(3):629-640.

3. Baskett TF, Nagele F. Bernhard Schultze and the swinging neonate. Resuscitation 2001;51(1):3-6.

4. Bloxsom A. Resuscitation of the newborn infant: use of the positive pressure oxygen-air lock. J Pediatr 1950;37(3):311-319.

5. Kattwinkel J, Perlman JM, Aziz K, Colby C, Fairchild K, Gallagher J. Part 15: neonatal resuscitation: 2010 American Heart Association Guidelines for Cardiopulmonary Resuscitation and Emergency Cardiovascular Care. Circulation 2010;122(18 Suppl 3);S909-S919.

6. World Health Organization. Guidelines on basic newborn resuscitation. Geneva: World Health Organization; 2012. http://apps.who.int/ iris/bitstream/10665/75157/1/9789241503693_eng.pdf?ua $=1$. Accessed July 30, 2015.
7. Liu L, Johnson HL, Cousens S, Perin J, Scott S, Lawn JE, et al. Global, regional, and national causes of child mortality: an updated systematic analysis for 2010 with time trends since 2000. Lancet 2012;379(9832):2151-2161.

8. Jayaram A, Sima A, Barker G, Thacker LR. T-piece resuscitator versus self-inflating bag for preterm resuscitation: an institutional experience. Respir Care 2013;58(7):1233-1236.

9. Bennett S, Finer NN, Rich W, Vaucher Y. A comparison of three neonatal resuscitation devices. Resuscitation 2005;67(1):113-118.

10. Finer NN, Rich W, Craft A, Henderson C. Comparison of methods of bag and mask ventilation for neonatal resuscitation. Resuscitation 2001;49(3):299-305.

11. Coffey PS, Saxon EA, Narayanan I, DiBlasi RM. Performance and acceptability of two self-inflating bag-mask neonatal resuscitator designs. Respir Care 2015;60(9):1227-1237 